\title{
CAMBIOS Y DIFERENCIAS EN LA ANDALUCÍA DE LOS NOVENTA
}

\author{
José Cazorla
}

Universidad de Granada

\begin{abstract}
RESUMEN
Se presenta en este trabajo una síntesis de la situación comparativa de Andalucía, en el contexto del conjunto de CC.AA. españolas, comentando algunos indicadores recientes significativos de sus desigualdades (interiores y ad extra), que no siempre deben ser asimiladas a las diferencias. En la gran mayoría de los casos aquéllas se registran desde hace más de cuatro décadas, y mantienen a la región más poblada de España en una situación de inferioridad socioeconómica que carece de justificación. Salvo por la presencia de factores tales como la escasa iniciativa empresarial, o la adopción de decisiones desde los círculos de poder, que no hace mucho han dado más importancia a las apariencias que a la resolución del fondo de los problemas laborales, de infraestructura y de producción que la atenazan. Los cuales, desde hace un siglo, mantienen a Andalucía en una posición que no cabe explicar en términos que ignoren su profunda, complicada y desigual realidad social.
\end{abstract}

\section{INTRODUCCIÓN}

Con motivo del sesenta aniversario del asesinato de Blas Infante, el Presidente Chaves declaró el 11 de agosto de 1996 a los medios de comunicación que "en Andalucía hay diferencias, pero éstas no implican desigualdades». Este discurso parece haber sustituido en los últimos tiempos a aquel que pocos años atrás proclamaba con rotundidad que Andalucía iba camino de ser la «California de Europa». Las reacciones a tan peregrina afirmación habían llegado 
incluso a la hilaridad colectiva, por ejemplo en una reunión de expertos celebrada en 1994 en Sevilla ${ }^{1}$. Lo que sí parece indudable es que en la Andalucía actual hay muchas diferencias y no menos abundantes e hirientes desigualdades, con lo cual es evidente que el señor Chaves no acertaba en su juicio. Después veremos hasta qué punto.

Las diferencias son también de magnitud histórica. Cuentan con unanimidad los historiadores que, en el mundo europeo y en toda la cristiandad, se produjo una verdadera conmoción cuando en 1492 ocurrió la toma de Granada. Conmoción que era tan auténtica como simbólica: el Islam quedaba al fin relegado al sudeste de Europa, a partir de la actual Serbia, con lo que se completaba la unidad político-religiosa de gran parte del espacio europeo. Solemnes celebraciones tuvieron lugar en Roma, Nápoles, Venecia, Londres y otras muchas ciudades, reflejándose con profusión en la literatura y romances de la época. La (re)conquista de Granada adquiría su merecido lugar en la Historia del mundo. Pero ese hecho objetivo, reconocido durante quinientos años, no fue obstáculo para que, justo cuando debió ser conmemorado donde y como se merecía, se le ignorara, en función de intereses muy particulares.

Viene este recuerdo a cuento porque cuando se celebró en 1992 el V Centenario (que no fue sólo del Descubrimiento de América, sino de la unificación de España y el fin de la Reconquista, coincidentes en 1492 en Granada), el único protagonismo que el Gobierno concedió a dicha ciudad en aquella fastuosa conmemoración fue una exposición de filatelia. Lo anecdótico del dato no le resta significación, porque, como es obvio, hay diferencias y desigualdades, unas sobrevenidas y otras provocadas.

Parece conveniente señalar aquí que, al redactar el presente trabajo, nos ha parecido preferible destacar aspectos de carácter preferentemente más «social» y político que económico ${ }^{2}$.

\section{DOS DÉCADAS DE CAMBIOS EN LA POBLACIÓN Y LA ECONOMÍA}

Iniciaremos este comentario con una referencia a la distribución espacial y concentración significativa de la población andaluza. No hay que resaltar su trascendencia por lo menos en los veinte últimos años y, a su vez, las modificaciones que sus tendencias han mostrado en particular en la pasada década. A tal efecto vamos a distinguir tres conjuntos distintos: la población residente en las ciudades, la del litoral y el resto (con especial atención a la de zonas de montaña). Considerando como zonas urbanas a las localidades superiores a

${ }^{1}$ Según cuenta J. Maestre Alfonso, en Andalucía 2020, p. 47. El panel de expertos al que consultó señaló como responsables del freno al desarrollo a la Administración y a la élite social andaluza.

2 Aparte de que los problemas del paro, el PER, la distribución sectorial de la población activa y similares han sido frecuente objeto de trabajos nuestros publicados con anterioridad en diversas revistas profesionales o libros. 
50.000 habitantes, en el Censo de 1991 residía en ellas un total de 3.188.725 personas, lo que equivalía a una proporción del 45,9 por 100 del total de la región. En 1981, esta proporción había sido del 43,6 por 100.

\section{CUADRO 1}

Población urbana en Andalucia, 1981-1991

\begin{tabular}{|c|c|c|}
\hline Población en miles & 1981 & 1991 \\
\hline $50-100$ & 649.019 & 586.377 \\
\hline 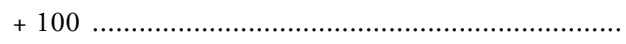 & 2.524 .004 & 2.602 .348 \\
\hline
\end{tabular}

Aparentemente, como se puede apreciar, en la década transcurrida se produjo muy escaso avance en la población urbana andaluza; incluso en las localidades de menos de 50.000 habitantes se registra un cierto retroceso. Pero la realidad es bien distinta. Lo que sucedió fue un reducido incremento de las ciudades de mayor tamaño, pero sobre todo crecieron los cinturones en torno a varias de ellas, como Granada, Málaga y Sevilla. En los cuales pequeños municipios hasta entonces de vida lánguida y economía agraria se convirtieron en ciudades-dormitorio, en un radio de hasta cincuenta kilómetros de la capital y a veces más, creándose a menudo verdaderas conurbaciones sin solución de continuidad. La mejora de transportes y comunicaciones, el alto precio del suelo y la creciente aspiración a disponer de viviendas unifamiliares (más o menos independientes, en cuanto "adosadas») impidieron un crecimiento de las ciudades propiamente dichas, similar al de las dos décadas anteriores, a la vez que localidades poco distantes de la ciudad se convertían en primeras o segundas residencias de un considerable número de habitantes urbanos. Con lo cual, entre otros fenómenos, perdieron su relativa independencia económica y asumieron a la vez modos y formas de comportamiento urbano. Circunstancia que en no mucha menor medida se transmitió tambien por vía especialmente de la televisión y otras comunicaciones al resto del mundo rural.

Naturalmente, no suele ser fácil determinar cuál sea el límite en que se pueda decir que acaba la ciudad y empieza «lo rural». Límite que hace unos treinta años estaba perfectamente claro en Andalucía y otras regiones españolas (aunque en otras nunca lo estuvo, como es el caso señero de Galicia). Aparte de que en el medio rural hay enclaves plenamente urbanos, como sucede, por ejemplo, con estaciones de invierno en Sierra Nevada, Pirineos u otras urbanizaciones de montaña. De hecho, sigue siendo cierto lo que hace casi tres décadas afirmamos, en el sentido de que lo rural y lo urbano son en mucha mayor medida «modos de vivir y no ubicaciones geográficas»"

\footnotetext{
3 J. CAZOrLA, en «Las subculturas rural y urbana», 1969.
} 
Un segundo conjunto de poblaciones es el que se encuentra a lo largo del litoral andaluz. Todavía a comienzos de los años sesenta abundaban los rasgos funcionales rurales en lugares como Marbella, Torremolinos o Mojácar, pero en la actualidad una parte de la costa sur se ha convertido en una sucesión de conurbaciones que sólo presentan algunos «huecos». Quiere decir que en aquéllas predominan los modos de vida y de producción urbanos en forma casi absoluta. De mayor magnitud incluso que en algunas capitales del interior de la Península, por ejemplo de la "Lusitania interior», o zonas de Galicia y Castilla. En definitiva, la mayor parte de los municipios que en el Atlas Económico de Andalucía 1992 alcanzan un nivel relativo de actividad más alto se encuentra precisamente en la costa.

A partir sobre todo de finales de los años cincuenta se produjo, como es sabido, una afluencia de población desde comarcas del interior a la costa (incluso a escasa distancia, como en el caso de la Serranía de Ronda), al acentuarse el contraste entre la escasez de recursos y empleo de aquéllas y ésta. Donde mejor se aprecia este contraste es en las provincias de Málaga, Granada y Almería, en las que se produce casi a todo lo largo de su perímetro marítimo un brusco salto entre la densidad y movilidad de la población, y también entre los niveles de renta de los municipios costeros y sus colindantes por el interior. A menudo a escasa distancia, aparecen aquellos con importantes aglomeraciones urbanas e ingresos p.c. superiores a la media nacional, frente a sus vecinos, que se encuentran aislados, con bajas capacidades de producción y población, e incluso dependientes de los "flecos» económicos que les puedan llegar de aquéllos. Como caso único entre las ciudades en el aspecto demográfico, esto sucede también en Almería capital, cuyos municipios colindantes al norte aparecen con fuertes tasas negativas intercensales de población.

Ampliando por un momento nuestra perspectiva, a efectos comparativos, y contemplando el "arco mediterráneo» que se inicia en el sur de Italia, vemos que allí lo caracteriza un relativamente bajo nivel de rentas, que aumentan en forma apreciable a partir de Roma, continúan con valores similares a todo lo largo de la costa italiana y francesa, siguen por el litoral catalán y valenciano, y sólo vuelven a disminuir al llegar a Andalucía, en el otro extremo del «arco». No obstante, tanto la variación intercensal de aumento de población 1981-91 como la renta familiar disponible son, comparativamente con el resto de la región andaluza y aun de España, relativamente altas en casi todos los mencionados 65 municipios costeros. Tanto la afluencia demográfica como el nivel de renta crecieron en el intervalo, por lo que se puede en general decir que el «arco» se prolonga hasta el límite con Portugal.

En el aspecto demográfico, el incremento de la franja litoral fue en aumento desde los años sesenta, en su práctica totalidad, casi siempre entre el 5 y el 18 por 100 de cada municipio en la década ${ }^{4}$. Hay algunas excepciones, que

${ }^{4}$ Véanse en detalle los respectivos mapas incluidos en el Atlas Económico de Andalucía 1992, editado por UNICAJA y ESECA. 
mencionaremos brevemente. Yendo de este a oeste, encontramos en el límite con Murcia los municipios de Vélez Blanco y Vélez Rubio, con un crecimiento entre cero y negativo, similar al de todos los que continúan hacia el interior, y que comentaremos después.

Pero la franja litoral "próspera» se inicia en Huercal-Overa y, pasando por Mojácar (uno de los municipios con relativamente mayor renta p.c. de Andalucía), continúa, salvando la zona protegida del Cabo de Gata, a lo largo de la costa este y sur de Almería. Tras las florecientes zonas de Nijar y Dalías, se llega a la provincia de Granada. En este límite encontramos una comarca, la de Albuñol, con cinco municipios deprimidos, expulsores de población y con muy bajos niveles económicos ${ }^{5}$. Se trata del único lugar, a lo largo de la costa sur española, que no solamente no ha tenido un desarrollo "normal» (turístico o de cultivos), sino que se encuentra en niveles de vida no muy distintos a los de hace tres o cuatro décadas. No está de más recordar que en octubre de 1973 esta comarca sufrió una catástrofe, por repentino aluvión en la rambla de Albuñol, que produjo más de cien muertos (incluidos los registrados en Adra y Puerto Lumbreras), y que fue rápidamente silenciada. Luego se reforzaron los márgenes de dicha rambla, pero la indispensable repoblación forestal continúa pendiente, así como diversas obras de consolidación y mejora entonces prometidas y nunca cumplidas ${ }^{6}$. La también pendiente autovía Adra-Nerja, que no se iniciará hasta el siglo XXI, es indispensable para el desarrollo de esta comarca. La cual de hecho no es más que el extremo sur de toda una zona deprimida, que ha expulsado población entre 1981 y finales de los noventa, y que se extiende a lo largo de más de doscientos kilómetros y tres provincias desde el límite con Murcia y Albacete. Más adelante volveremos a referirnos a dicha zona.

En situación considerablemente mejor se encuentran en la provincia de Málaga los municipios de Torrox y Algarrobo, que presentan un movimiento demográfico positivo, pero no tanto en lo referente a sus aparentes rentas familiares disponibles p.c. Y en la de Cádiz, ya en la costa atlántica, los de Conil, Vejer y Barbate, de características similares en lo económico. De manera que salvo en estas pequeñas excepciones, es decir, 10 (o menos) de los 65 municipios de la costa andaluza, su población reside en localidades con un nivel superior a la media de las rentas familiares, entre ellas ciudades como Almería, Málaga, Algeciras y Cádiz. Nivel que en algún otro tramo, como es el de Marbella-Estepona, resulta también bastante alto ${ }^{7}$.

5 Tales municipios son Lujar, Rubite, Polopos, Sorvilán y Albuñol.

${ }^{6}$ No está de más el recordar que la pendiente media de estos cinco municipios es del 45 por 100, según el Atlas..., cit. Lo que da una idea no sólo de la urgente necesidad de su repoblación, sino del peligro que siguen corriendo sus habitantes ante cualquier fenómeno meteorológico como el de 1973.

7 La construcción masiva de urbanizaciones y altos bloques de pisos a lo largo de buena parte de la costa sur y mediterránea ha producido un impacto ecológico irremediable y contrario a menudo a un elemental sentido de calidad de vida. Se ha arrasado la Naturaleza y se han violado las leyes construyendo mucho más allá de lo que éstas permitían. Uno de los resultados ha sido la desaparición de playas enteras, que obligan al Estado y a las CC.AA. a gastar miles de millones en regenerarlas cada año a costa no de los promotores sin escrúpulos, sino de los contribuyentes. 
Cabe distinguir una tercera zona, aparte de las ciudades del interior y la franja costera mencionadas, en la que se perciben fácilmente dos niveles de vida: uno intermedio, como es el Valle del Guadalquivir, la zona de LinaresÚbeda y la mayor parte de las provincias occidentales; y otro nivel realmente bajo correspondiente a las altiplanicies y zonas montañosas de éstas, generalmente situadas en su extremo norte, así como casi todo el tercio este de la región. El cual comprende más de dos tercios de las provincias de Almería y Granada y la mitad aproximadamente de las de Jaén y Málaga, especialmente en zonas montañosas. Los cambios perceptibles en todas estas comarcas coinciden en señalar una población decreciente, en rápido envejecimiento, con fuerte dependencia de subsidios o pensiones, y una economía tradicional, escasamente innovadora ni competitiva. Con algunas pequeñas «islas», este conjunto abarca probablemente la zona de menores niveles de renta y mayor extensión del país. Aquí las desigualdades, además de las diferencias, son obvias.

Según se deduce del mencionado Atlas, más de la mitad de los municipios de Granada, Jaén y Málaga no llegaban a mediados de los años noventa al nivel aproximado medio de renta familiar de la región, lo que es claramente indicativo del contraste al que antes nos referíamos. Igualmente, su ubicación coincidía en los dos primeros y Almería con la zona interior que ya hemos comentado y, en Málaga, con la mayor parte de la superficie también interior de la provincia, con las salvedades de los municipios de Antequera y Ronda, relativamente menos deprimidos. En las demás provincias, el número de localidades con dichos niveles medios es mucho menor.

Si bien el total de municipios en tal situación es del 38,2 por 100, desde luego la población a que corresponden es bastante menor, dado que la mayoría de ellos son de pequeño tamaño. Pero tampoco se puede olvidar que, según el INE, en 1990 Andalucía tenía un 24,49 por 100 de personas «bajo el umbral de pobreza», frente al conjunto nacional, en que tal proporción bajaba al 15,16 por 100. Es claro que, en coincidencia con otros indicadores - alguno de los cuales comentaremos también-, era en esta zona rural de montaña de Andalucía (en especial en sus provincias orientales) donde con mayor frecuencia se daban a comienzos de la década menores ingresos familiares p.c. ${ }^{8}$.

Datos más recientes de La Caixa (1997) ofrecían un singular contraste entre las rentas familiares disponibles por habitante, según niveles económicos, por municipios de Andalucía y España en 1994 (últimas cifras disponibles). En efecto, como ya hemos apuntado, sólo dos municipios de Almería (Mojácar y Dalías), entre el total de 770 municipios andaluces, llegaban al nivel 4 (de 1.000 .000 pts. a 1.100 .000 pts.), entre los diez niveles de renta previstos, correspondiendo el último a una media de 1.600 .000 pts. p.c. o más. Todos los demás se quedaban en los tres primeros niveles, inferiores por tanto al millón de pesetas p.c. En Cadiz, sólo el 2,6 por 100 de la población se encon-

8 El simple repaso de las características socioeconómicas de los municipios contenidos en el Atlas..., cit., así lo confirma, sin que aquí nos sea posible entrar en su detalle. 
traba entre 900.000 pts. y un millón, y en Málaga esta proporción era también muy baja, con el 7,3 por 100. La comparación con España en su conjunto resulta abrumadora. Así, aparece en estos tres primeros niveles sólo el 38,5 por 100 de la población española, seguido por el 40,82 por 100 en los niveles 4 a 6 (de 1.000 .000 a 1.300 .000 pts.), y por encima de ellos otro 14,7 por 100, hasta la mencionada renta de 1.600 .000 o más.

Hay CC.AA. como País Vasco, Navarra, La Rioja, Cataluña y Baleares en que la población que se encuentra en el nivel 5 (1.100.000 a 1.200.000) es insignificante, porque la práctica totalidad de ella está por encima del mismo. Es decir, exactamente lo contrario de lo que sucede en Andalucía, en que toda queda por debajo

El problema de fondo, que sólo podemos aquí mencionar de pasada, es que en Andalucía, «intencionadamente o no, no se han creado oportunidades de empleo en nuestro medio rural, y considerables cantidades han venido destinándose a una economía subsidiada e improductiva, en torno a la cual se ha creado una cultura económica parasitaria y nefasta» (J. Cazorla, 1995).

En todo caso, conviene también señalar que en 1991 se lanzó la iniciativa comunitaria LEADER con el fin de estimular el desarrollo integral de zonas atrasadas de la Unión Europea, para lo que se aúnan ayudas financieras procedentes de los tres Fondos Estructurales, con aportaciones paralelas de los países implicados, tanto públicas como privadas. Se han concedido "Centros de Desarrollo Rural» (CEDER) a todas las CC.AA. En 1992, la Comisión Europea aprobó nueve Programas para otras tantas áreas andaluzas, entre las que destacan La Loma de Úbeda y Baeza y la Alpujarra. Abarca esta última 55 municipios, entre ellos buena parte de los incluidos en la zona demográfica y económicamente deprimida a que antes nos referíamos. La cantidad comprometida para la Alpujarra alcanza los 295.156 millones de pesetas, con un total de 95 proyectos aprobados (ya en la primavera de 1993), y particular inflexión en aspectos de desarrollo turístico. Este programa ha conseguido aprobación de la Comisión para su continuación en el LEADER II (1994-99), junto a tres comarcas de Jaén (Sierra Mágina, El Condado y Segura). Este tipo de iniciativas, cuyo detalle se sale de nuestro propósito aquí, constituye un importante paso para la futura promoción de comarcas andaluzas deprimidas, no sólo como ejemplo teórico a seguir, sino como demostración práctica de sus posibilidades ${ }^{10}$.

9 Véanse en particular los gráficos y mapas provinciales que ofrece esta publicación de La Caixa en sus pp. 190-199. Por otro lado, J. Torres López, en el Anexo del artículo que citamos en la bibliografía (1995), ofrece a su vez interesantes datos estadísticos sobre los niveles de pobreza dentro de Andalucía. Entre ellos merece destacarse el cuadro 9, según el cual deben ser considerados como "pobres» nada menos que «el 52,6 por 100 de los parados, el 24,6 por 100 de los pensionistas, y el 29,5 por 100 de los habitantes de núcleos no urbanos», lo que coincide con nuestro análisis precedente.

${ }^{10}$ Para mayor detalle respecto a la aplicación de los Planes LEADER pueden verse los artículos de Barke y Newton y Ruiz Avilés y Ulecia García publicados en 1995 en la $R E R$, que cita- 
Un apartado especial hay que dedicar al problema de las migraciones, como fenómeno nuevo en la región y que produce un subproletariado al que es preciso prestar suficiente atención, en especial por las peculiares circunstancias de Andalucía. Resulta curioso que ésta fuese la región española de mayor emigración a Centroeuropa en los años 1959-1974, según nuestra estimación, con aproximadamente un 40 por 100 de la total española. Y sólo una década después se cambian las tornas y se convierte en área de inmigración. Y ello a pesar de que sigue siendo la región de más alto desempleo de la UE. Desde 1985 se viene percibiendo la creciente presencia de inmigrantes extranjeros, entre los que predominan con mucho los de origen marroquí, al igual que en el resto de España. Dicho de otro modo, desde mediados de los años ochenta Marruecos es el país que más inmigrantes laborales aporta a España. A 31/12 de 1994 había en total 44.958 con permiso de trabajo (la mayor proporción por nacionalidad, 36,9 por 100); de ellos, 4.725 en Andalucía. La mitad procedían de las provincias del norte de Marruecos (lo que les proporcionaba la ventaja de conocer el idioma español por vía de TVE), una quinta parte eran mujeres y residían sobre todo en las provincias de Málaga y Almería. En su mayoría se encontraban entre los 25 y 35 años y se dedicaban principalmente a trabajos agrícolas, domésticos, venta ambulante y pesca (J. Cazorla y J. Montabes, 1996).

Se sabía que un número probablemente superior al de "regularizados» trabajaba clandestinamente en España, a donde hasta entonces habían entrado con la simple presentación del pasaporte. La exigencia del visado coincidió con un acuerdo entre ambos países, en diciembre de 1992, por el que se fijaba una «cuota» anual de 20.600 inmigrantes, y se comprometía el Gobierno marroquí a «intensificar» su vigilancia. Con ello se evitaba la entrada de clandestinos y también su frecuente desaparición al intentar cruzar en las más precarias condiciones. Por entonces nos preguntamos cuánto tiempo duraría la "vigilancia» marroquí (J. Cazorla, 1995b). En efecto, desde comienzos de 1996 volvió a producirse una oleada de intentos de entrada clandestina, que en los meses de verano de 1996 y 1997 ha superado el medio millar semanal ${ }^{11}$. La costa de

mos en la bibliografía. Sobre la situación en general del medio rural andaluz y algunos cambios significativos ocurridos en él puede consultarse nuestro trabajo «Estructuras y relaciones de poder en el medio rural español» (1996), en que se presta particular atención a la región andaluza.

${ }^{11}$ Sólo en los primeros dieciocho días de agosto de 1996 fueron detenidos, en la costa de Cadiz, 480 inmigrantes «ilegales», sin que se sepa cuántos pudieron en realidad no ser detectados, aunque según algunas fuentes "pasan» tres por cada uno que es detenido y luego expulsado. El 23 de agosto de 1996 terminó un nuevo período de «regularización» para los «ilegales» residentes, a quienes para conseguirlo se les exigía que se encontrasen en el país antes del 1 de enero de 1996, que fuesen parientes de otros ya legalizados y que hubiesen tenido un permiso anterior de trabajo en España. El número de los que se acogieron a esta regularización fue bastante menor de lo que se preveía (lo hicieron en total 24.389, de ellos unos 8.000 marroquíes, que constituyen el grupo más numeroso). Un procedimiento que lleva años usándose es que las mujeres marroquíes no residentes en Ceuta o Melilla vayan al hospital de estas ciudades a dar a luz, registrándose por tanto allí sus hijos. Los cuales, llegados a la mayoría de edad, pueden acogerse a la nacionalidad española. 
Andalucía se ha convertido así en el punto de fricción entre dos mundos, el Norte y el Sur, el desarrollado y el no desarrollado, situados a tan sólo 14 kilómetros de distancia, pero con rentas p.c. (Marruecos-España) en proporción de 1 a 13,5, y fuertes diferencias de empleo y natalidad.

El hecho de que dediquemos ahora un corto espacio a comentar tal circunstancia no se debe tanto a su mera cuantificación, sino a un significado más profundo. En efecto, hasta este momento España es proporcionalmente uno de los países de Europa con menor volumen de inmigrantes ${ }^{12}$. Pero la cuestión radica en el previsible incremento de la presión inmigratoria, que se puede usar como arma política, tal y como se deduce de sus altibajos en ciertos momentos de crisis en las relaciones Norte-Sur, y más en concreto MarruecosEspaña. En algún momento tal presión puede llegar a asemejarse a la que hace tres o cuatro años se produjo en la costa este de Italia, con la llegada repentina de miles de inmigrantes albaneses, o la frustrada salida de cubanos hacia Florida. No es un problema andaluz, desde luego, sino español y de la UE, pero su "primera línea», evidentemente, se encuentra en la costa andaluza, con todas sus consecuencias (además de en Ceuta y Melilla). Al igual que otra "primera línea» se enfrenta a la presión migratoria desde el Este en las fronteras orientales de Alemania y Austria. Lo que merece comentarse al respecto es que, hasta ahora, la UE ha prestado gran atención a estos últimos movimientos, mientras que no parece dar gran importancia a la «frontera sur». En la cual puede en cualquier momento provocarse un problema internacional de gran envergadura.

\section{OTROS INDICADORES DE CAMBIO}

Muy estrechamente relacionados con los ingresos se encuentran dos conocidos indicadores: el consumo eléctrico y el número de líneas telefónicas.

En consumo eléctrico, Granada ocupa el punto más bajo y, además (con la excepción señalada de Huelva), con apreciables diferencias entre las diversas provincias. En cuanto al número de líneas telefónicas por 100 habitantes, el índice más bajo corresponde a Jaén. Una vez más, aparecen éstas como las dos provincias más deprimidas de la región. Si comparamos con el conjunto nacional, resulta que éste daba una cifra de 4,05 Mwh para el mismo año, como consumo medio de energía eléctrica. El cual supera, por tanto, en un 37 por 100 al consumo andaluz, que viene a ser similar al medio de Portugal. En cuanto a las líneas telefónicas, el promedio nacional era de 37,1 , lo que impli-

12 Se puede calcular con cierta aproximación en más de medio millón el número de inmigrantes laborales (y no procedentes de la UE) actualmente en España. Datos recientes sobre sus características personales aparecen en Estadística de permisos de trabajo a extranjeros, 1994, M. ${ }^{\circ}$ de Trabajo y Asuntos Sociales, 1996. Respecto a las posibilidades de una fructífera cooperación internacional que contribuyera a paliar el problema de la inmigración pueden verse las sugerencias contenidas en nuestro trabajo «La inmigración marroquí en España: datos, opiniones y previsiones», RIS, núm. 13, 1995. 
ca una inferioridad andaluza del 24 por 100, aproximadamente. En el caso de Granada y Jaén — puesto que estamos hablando de desigualdades-, la primera consumía en 1994 un 56 por 100 menos energía eléctrica que la media nacional, y Jaén tenía un 33 por 100 menos de líneas telefónicas que dicho promedio. El comentario sobra al obtener tan importantes y básicas muestras de desigualdad, y eso sin necesidad de comparar más que con la media del país, y no con provincias más favorecidas por la suerte o por la clase política ${ }^{13}$.

\section{CUADRO 2}

Consumo eléctrico y lineas telefónicas. Andalucía, 1994

\begin{tabular}{|c|c|c|}
\hline Provincias & Consumo eléctrico & Lineas telefónicas \\
\hline Almería ................... & 2,40 & 28,3 \\
\hline 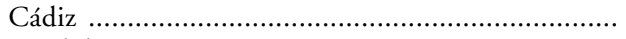 & 2,92 & 25,7 \\
\hline Córdoba …................................. & 2,22 & 26,4 \\
\hline 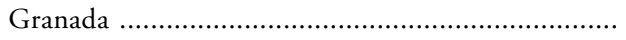 & 1,78 & 28,6 \\
\hline 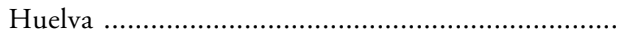 & 5,00 & 25,8 \\
\hline 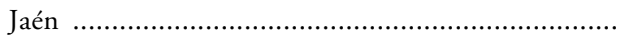 & 2,20 & 24,8 \\
\hline 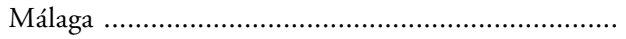 & 2,20 & 32,2 \\
\hline 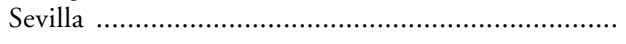 & 2,51 & 28,8 \\
\hline Andalucía ........ & 2,56 & 28,4 \\
\hline
\end{tabular}

Fuente: Calculado sobre datos primarios contenidos en Población de derecho según Padrón Municipal de Habitantes (al 1/1/94), Cía. Sevillana de Electricidad (1994) y CTNE (al 31/12/94). El consumo eléctrico está expresado en Mwh por habitante, y el número de líneas telefónicas es por 100 habitantes. La alta cifra de consumo de Huelva se reduce a menos de la mitad si se descuenta el consumo energético de Minas de Riotinto y Palos de la Frontera, cuya población es de unos 12.700 habitantes en total.

Con motivo de las conmemoraciones del 92, por otra parte, se construyó una esencial red de autovías en la región, que la han conectado con Levante en 1997 y que aún está pendiente de terminar en su conexión Norte-Sur. La financiación de este tramo depende no de la CA, sino del Estado, y su fuerte retraso coincide, no por casualidad, con la provincia de Granada. El vital trayecto Durcal-Motril es dudoso que esté finalizado para antes del 2003. Tampoco se encuentran suficientemente avanzados los planes para el tramo de la autovía de la costa Adra-Nerja, correspondiente en su mayor parte también a la provincia de Granada.

${ }^{13}$ Datos nacionales obtenidos en Anuario El País, 1996. No se pierda de vista que -a los efectos de consumo eléctrico-, tanto para refrigeración como para calefacción, el clima de Granada y Jaén, que se encuentran entre las provincias más montañosas del país, es más riguroso que el de otras situadas en su mayor parte en el valle del Guadalquivir o en el litoral. 
Para no referirnos más al tema de las comunicaciones, nos limitaremos a recordar que el ferrocarril Almería-Baeza y Granada-Baeza sigue usando las mismas vías de su inauguración (de la que en 1998 se ha cumplido un siglo) y un material rodante de desecho de otras líneas. El trazado impide velocidades medias superiores a los $55 \mathrm{~km} /$ hora, con lo cual, para poner un solo ejemplo cotidiano, se tarda aproximadamente lo mismo en el trayecto Granada-Baeza que en el Sevilla-Madrid, en el AVE, que es casi tres veces más largo pero, además, mucho más cómodo. Es éste, en suma, un servicio básico en el que no ha habido cambios dignos de mención en las provincias de Granada y Almería y en el que, por tanto, la desigualdad se acusa comparativamente más.

Pasando a otros aspectos, un contraste que llama la atención es el de los depósitos bancarios, según el cual, y contra lo que en principio cabría esperar, algunas de las provincias menos desarrolladas son precisamente las que poseen mayor base financiera privada.

\section{CUADRO 3}

Depósitos bancarios en Andalucía, sector privado, 1995

\begin{tabular}{|c|c|c|}
\hline Provincias & Total depósitos & Depósitos/habitante \\
\hline Almería ........ & 466 & 945 \\
\hline Cádiz ............ & 675 & 598 \\
\hline Córdoba .... & 708 & 905 \\
\hline Granada & 703 & 835 \\
\hline . & 339 & 738 \\
\hline Jaén & 564 & 845 \\
\hline 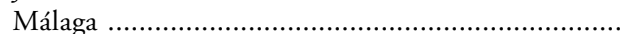 & 902 & 736 \\
\hline 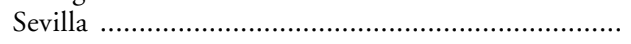 & 1.279 & 744 \\
\hline Andalucía ....... & 5.636 & 770,5 \\
\hline
\end{tabular}

FUENTE: Elaborado sobre datos primarios de Informe ESECA 1996. El total de depósitos de Banca privada, C. de Ahorros y Postal y Cooperativas de Crédito figura en miles de millones de pesetas. Los depósitos por habitante se han registrado en miles de pesetas.

Se puede apreciar en esta tabla cómo Almería figura en cabeza de los depósitos privados p.c. (según fuentes fiables, contaba nada menos que con 30.000 millones de pesetas, en su mayoría en entidades de su costa sur), seguida por Córdoba, Jaén y Granada. Los primeros puestos p.c. no los ocupan, frente a lo que se podría suponer, Sevilla ni Málaga. Lo cual es indicio de que por lo menos en Córdoba, Jaén y Granada existe una fuerte desigualdad provincial interior que hace que una capa alta de la sociedad haya mantenido inmovilizados fuertes depósitos en las entidades de crédito, mientras que proporcionalmente tales depósitos eran menores en otras, bien por su mera cuantía o bien 
por encontrarse invertidos en empresas productivas. A la vez, la pobreza media es relativamente mayor en Almería, Jaén y Granada, lo que significa mayor "distancia» interior entre los que tienen y los que no tienen. Dicho de otro modo, se trata del conocido síntoma de mayor "altura» de la pirámide social, característica de las zonas menos desarrolladas de países o regiones ${ }^{14}$.

El gasto probablemente más representativo de lo que suele llamarse «cultura» es la adquisición de libros, diarios, periódicos y revistas. No disponemos de datos posteriores a 1990, pero las siguientes cifras son significativas y no hay indicios de que hasta el presente hayan cambiado mucho. Incluimos también ciertas producciones editoriales.

\section{CUADRO 4}

Gasto anual medio en material de lectura y producción editorial

\begin{tabular}{|c|c|c|}
\hline Provincias & Pts/habit. (1990) & Prod. edit. (1992) \\
\hline Almería ...................... & 5.636 & 113 \\
\hline Cádiz & 4.706 & 175 \\
\hline Córdoba & 7.696 & 417 \\
\hline (2) & 3.237 & 465 \\
\hline 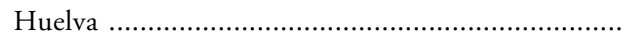 & 8.306 & 73 \\
\hline Jaén ....................... & 1.622 & 156 \\
\hline 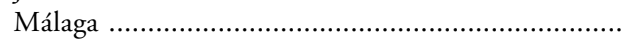 & 4.525 & 431 \\
\hline Sevilla & 4.561 & 576 \\
\hline 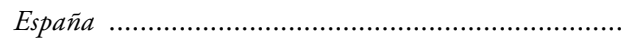 & 6.759 & - \\
\hline
\end{tabular}

Fuentes: INE, Encuesta de Presupuestos Familiares 1990-91, y Consejería de Cultura y Medio Ambiente (1992). El material de lectura comprende libros, diarios, periódicos y revistas. En la producción editorial sólo se han computado monografías y publicaciones periódicas, pero no postales, folletos, carteles, mapas ni hojas sueltas.

Aun teniendo en cuenta los precios de hace ya varios años, realmente el gasto en lectura de los andaluces era insignificante. El cual se aproximaba a una media española tampoco muy alta. Este dato coincide con un estudio nuestro por encuesta (1991), en el que resultaba que el 48,7 por 100 de los andaluces declaraba que no dedicaba «ningún tiempo» a la lectura de libros o narraciones, y el 33,2 por 100 decía lo mismo de periódicos o revistas. Llama

${ }_{14}$ Datos similares hemos comentado en «El marco económico y la política social en Andalucía, 1995». El resultado habitual es que la zona se estanca porque quienes mayor poder, influencia y/o dinero poseen no tienen siquiera una mentalidad capitalista, que se arriesga a cambio de un mayor beneficio. Tampoco se movilizan en favor de iniciativas novedosas, e incluso a menudo sabotean las que surgen. En cuanto a los depósitos bancarios de Almería, en su mayor parte son atribuibles al intenso tráfico económico derivado de los cultivos de su floreciente costa sur. 
la atención la bajísima cifra de Jaén (que hasta hace algunos años era la provincia española con mayor grado de analfabetismo). En cuanto a la escasa producción editorial, queda Huelva en último lugar de la región.

Una interesante iniciativa, comenzada hace ya cuatro años, fue la promoción del "Legado andalusí», serie de rutas que intentaban fomentar el interés por un turismo cultural en profundidad que superara los trillados, apresurados y masificados circuitos de las agencias. Su eje partiría de Granada, y si su originalidad hubiera tenido algún soporte real en la Administración hubiera producido importantes beneficios a la economía de la región. Actualmente se está intentando revitalizarlo, pero es preciso un apoyo decidido de la Administración, al menos en su inicio.

Otro indicador que recogemos en esta sección es el que vamos a referir brevemente a los funcionarios de la Administración autonómica. Para ello hemos computado el número total de éstos en las cuatro CC.AA. de plena autonomía, calculando luego el número de funcionarios por 1.000 habitantes. El resultado es el siguiente.

\section{CUADRO 5}

Funcionarios autonómicos por 1.000 habitantes en cuatro CC.AA., 1993

\begin{tabular}{|c|c|c|}
\hline Comunidades Autónomas & Total func. aut. & Func. aut./1.000 hab. \\
\hline Andalucía & 176.413 & 25 \\
\hline Cataluña . & 103.742 & 16 \\
\hline 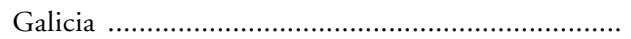 & 59.132 & 21,7 \\
\hline 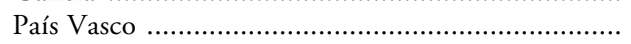 & 43.818 & 20,8 \\
\hline
\end{tabular}

FUENTE: Elaborado sobre datos primarios del Boletín Estadístico del Registro Central de Personal, 1993.

Vale la pena comprobar que el número de funcionarios en la Administración autonómica andaluza supera bastante la proporción de las otras tres, siendo la menos nutrida la catalana. Cabe preguntarse qué causas pueda haber en el origen de esta diferencia y si repercute en una mayor eficiencia de la Administración andaluza. Una posible explicación parcial estaría en la mayor extensión de la región, compuesta por ocho provincias, frente a las otras CC.AA. Desde luego, es difícil encontrar datos o pruebas que avalen una mayor o menor eficacia comparativa de las respectivas Administraciones. Lo que en todo caso resulta evidente es que el peso específico de este cuerpo de funcionarios, proporcionalmente más numeroso en Sevilla, ha otorgado a esta ciudad una importante base económica permanente de ingresos que contribuye a potenciar su economía, con diferencia apreciable respecto a las otras capitales y provincias. 
Un último indicador que vamos a recoger aquí es el correspondiente a los gastos municipales por habitante. Sobre datos de 1993, aparece una apreciable desigualdad entre las provincias andaluzas y, a su vez, con todo el cuadrante noreste del país. En efecto, cinco provincias de esta región (Huelva, Sevilla, Córdoba, Jaén y Granada) aparecen en el penúltimo tramo de dichos gastos, entre 60.000 y 69.000 pts. por habitante. (En ese mismo nivel figuran la gran mayoría de las provincias de la mitad oeste de España.) Entre 70.000 y 79.000 están Cádiz y Almería, y la de mayor gasto es Málaga, situada entre 80.000 y 89.000 pts. Conviene recordar aquí el ambicioso Plan Estratégico detalladamente proyectado para modernizar esta ciudad en los próximos años, con un presupuesto superior a los 600.000 millones de pesetas. Cinco provincias del noreste partían como mínimo de presupuestos similares a éste, otras dos pasaron al tramo siguiente de 90.000 a 99.000 pts., y cinco superan las 100.000 pts. $y$, por tanto, gastaron por habitante más de un tercio por encima de la mayoría de las andaluzas.

Abarcan todas esas provincias el País Vasco, Navarra, la mayor parte de Aragón y Cataluña ${ }^{15}$. Inferioridad de servicios municipales a disposición de los ciudadanos andaluces, frente a otras regiones, en suma, y aun desigualdades considerables entre ellos mismos, como vemos.

\section{ALGUNOS DATOS POLÍTICOS}

Las últimas elecciones de la II República se celebraron, como es sabido, en febrero de 1936. En ellas, el Frente Popular obtuvo en Andalucía la mayoría absoluta. Sesenta años después, y tras obtener mayorías favorables a los partidos de izquierda en la región en todos los comicios celebrados desde 1977, se han reiterado similares resultados en las últimas elecciones generales, en marzo de 1996. Se han agrupado en dos bloques para mayor facilidad de comparación.

Para algunos puede ser discutible el incluir en la derecha al PA, pero, en todo caso, habitualmente no se ha considerado a este partido como de izquierda. Recuérdese su cambio de PSA a PA. Por otra parte, lo que más cuenta es la indiscutible adscripción a la izquierda de PSOE e IU. El hecho de que actualmente el PA actúe en coalición con el PSOE es coyuntural, como ya ocurrió hasta 1996 con la alianza para el gobierno central de PSOE y CiU. Los datos que incluimos respecto a los resultados por provincias muestran que en todas venció con holgura la izquierda, quedando en primer lugar Sevilla y en el último, pero todavía con 15 puntos de diferencia, Almería.

Lo que queremos subrayar es la persistencia de la opción de izquierda en Andalucía, especialmente en su medio rural, a través del paréntesis franquista,

15 Datos procedentes de Memoria de la Dirección General de Análisis Económico Territorial, 1993. 


\section{CUADRO 6}

Elecciones generales. Andalucía, 1996

\begin{tabular}{|c|c|c|}
\hline Provincias & Izquierda & Derecha \\
\hline Almería & 57,01 & 41,86 \\
\hline Cádiz ...... & 57,06 & 41,44 \\
\hline Córdoba ......... & 63,21 & 35,68 \\
\hline 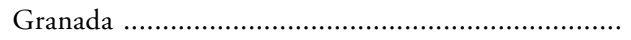 & 58,47 & 40,31 \\
\hline 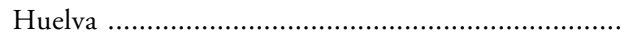 & 62,36 & 36,60 \\
\hline Jaén & 60,40 & 38,59 \\
\hline 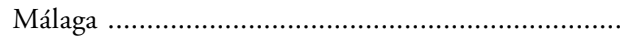 & 57,20 & 41,20 \\
\hline Sevilla & 63,46 & 34,95 \\
\hline
\end{tabular}

NotA: Se han considerado sólo los cuatro partidos más votados, que además obtuvieron representación parlamentaria en Andalucía. Se han agrupado los votos por tendencias, sumándose en la izquierda a PSOE e IU-LV-CA, y en la derecha a PP y PA.

y por tanto con una tradición que se remonta por lo menos a $1936^{16}$. A esta tradición no es ajeno el sentimiento de desigualdad en el interior ${ }^{17}$ y también en el exterior de Andalucía, que no ha disminuido en los últimos diez años, y que contrasta con los preceptos de la Constitución, del Estatuto y con las profusas declaraciones de los políticos ${ }^{18}$. Aparte del desgaste de la permanencia en el poder durante quince años, es lógico que quienes disfrutan de mejores servicios (relativamente) en los centros urbanos hayan preferido en las elecciones de los últimos siete u ocho años optar por una alternativa distinta (no tanto ideológica, como la única opuesta con suficiente presencia a la que había decepcionado). Pero las elecciones de 1996 nos enseñaron que la opción de izquierda mantiene una presencia indiscutible en 11 de los 20 municipios de más de 50.000 habitantes, y también en la mayoría de los que quedan por

${ }^{16}$ Sin perder de vista la abismal distancia que media entre ambos comicios y ambas sociedades. Derecha e izquierda eran tan radicales en sus respectivas posiciones que su irreconciliable postura en 1936 terminó casi de inmediato en una guerra civil. A ello las condujeron una ideología de revancha e intolerancia y una estructura que conducía a la lucha de clases. Cuando se producen las primeras elecciones democráticas, en 1977, la cultura política ha cambiado por completo (salvo en pequeñas minorías), y la estructura se ha equilibrado con una extensa clase media nueva y mucha menor "distancia» entre los extremos de la pirámide social.

17 El llamado "agravio comparativo" ahora sólo es mencionado por los dirigentes políticos en Sevilla con relación a regiones más prósperas, como Cataluña, pero nunca se le cita respecto a la situación interior andaluza.

${ }^{18}$ Según un Informe de ESECA, citado por J. Torres López, «la población [andaluza] residente en comarcas que tienen una renta p.c. inferior al 75 por 100 de la renta regional, pasó de ser el 4,2 por 100 en 1981 al 14 por 100 en 1989, de manera que... se produce un aumento de la concentración y la desigualdad en la distribución de la renta p.c. tomando a la comarca como unidad de análisis». 
debajo de esta población. Sumando los respectivos sufragios, la opción de «izquierda» consiguió 2.600.827 votos (60,14 por 100), y la de "derecha» 1.664 .857 votos $(38,50$ por 100$)$. Como decimos, sesenta años después del comienzo de la guerra civil, Andalucía ha mantenido mayoritariamente una posición coherente con su tradición política y, desde luego, con su situación socioeconómica ${ }^{19}$.

Factor decisivo al respecto ha sido — como hemos señalado- su ya secular desigualdad y, además, la potente implantación de la «máquina» del PSOE, que ha llegado hasta los más pequeños rincones de la región, y su consiguiente capacidad de movilización. Igualmente, las mejoras unas veces cosméticas y otras reales del medio rural, que han "lucido» más en él en comparación con las realizadas en las ciudades, y las subvenciones al desempleo, que por primera vez han sostenido en un nivel de economía digna a campesinos parados. La situación ha cambiado: como consecuencia de las subvenciones oficiales, PER y similares, el tradicional enfrentamiento jornaleros-propietarios ha sido sustituido por el de jornaleros-Administración. Las presiones y reivindicaciones de subsidios se plantean ahora sobre todo ante las autoridades municipales, dejando a un lado a la patronal. Por otro lado, quienes cobraban indebidamente tales subvenciones también han apoyado al nuevo patrono, el partido (que sustituía al antiguo, el cacique), en una postura que nada ha tenido que ver con las ideologías y sí mucho con los intereses personales. Si las nuevas medidas de protección que modifican el antiguo PER van en lo sucesivo a aplicarse rigurosamente sólo a los parados, se habrá saneado no sólo la economía, sino la ética de la Administración pública y política de la región. No creemos que por un tiempo previsible tales medidas impidan a la izquierda mantener su predominio, el cual posee una base bastante más sólida que el apoyo de unos miles de «aprovechados» que han cobrado lo que no les correspondía. Tampoco se olvide que en otras regiones, más al norte, se vienen produciendo situaciones parecidas, mucho menos denunciadas que la de Andalucía ${ }^{20}$. Un ejemplo al respecto lo encontramos en una investigación que hemos realizado en torno al clientelismo político en España durante más de tres años ${ }^{21}$.

Parte del estudio se ha realizado sobre dos localidades de algo menos de 50.000 habitantes, situadas una en Andalucía y la otra en una CA diferente, cuyos gobiernos municipales han correspondido, respectivamente y sin solu-

19 Una pormenorizada relación de las distintas elecciones celebradas en Andalucía desde 1977 a la actualidad puede encontrarse en J. MONTABES, «La concurrencia electoral en Andalucía” (1996).

${ }^{20}$ Véase con mayor detalle nuestra perspectiva de este tema en el trabajo antes mencionado «Estructuras y relaciones de poder...» (1996).

${ }^{21}$ Se trata de una investigación patrocinada por la Fundación Volkswagen y realizada con la colaboración de los profesores M. Jerez y J. Montabes, así como de la licenciada S. Corzo. La bibliografía propia pertinente al clientelismo consta aparte en la que aparece al final del presente trabajo. Los resultados que aquí muy brevemente expongo son atribuibles conjuntamente a los autores. 
ción de continuidad desde las primeras elecciones locales, a los dos partidos mayoritarios en el país. En ambas poblaciones se detectan variedades de clientelismo político, que se concretan en la forma de obtención del empleo público, la concesión de subvenciones o la contratación de obras públicas. Tales concesiones no producen reacciones públicas en contrario, ya que socialmente se consideran inherentes a los procesos de selección de personal o contrata de obras habituales. En uno de los municipios se buscan de este modo no sólo apoyos electorales, sino fidelidades intrapartidistas, mientras que en el otro sólo los primeros, pero con mayor propensión al nepotismo y al amiguismo. Los medios utilizados para mantenerse en el poder varían también en uno y otro. En el primero se procura que los líderes de asociaciones voluntarias coincidan con los líderes del partido en el poder, controlándose así las demandas y apoyos ciudadanos. En el otro municipio, de orientación más conservadora, se tiende más bien a frenar cualquier asociacionismo, reforzándose así las relaciones de dependencia tradicionalmente vinculadas a las familias más pudientes.

En ambas poblaciones se evalúan en exceso ciertos méritos en función del candidato que previamente se va a seleccionar. Para ello se sobrevalora a los interinos (que entraron discrecionalmente) y que responden al perfil ideológico previsto por el empleador público. Sin poder aquí resumir siquiera lo que es un prolijo y extenso trabajo de investigación, se observa, en resumidas cuentas, que en el municipio gobernado por la derecha el apoyo electoral se consigue más bien a través de los contratadores privados, sin tener que recurrir a los empleados públicos. En cambio, en el muncipio con predominio de izquierda, al no coincidir los líderes económicos y políticos, los apoyos se logran a través de ayudas sociales, bonificaciones, empleo público e incluso ciertas obras públicas. El hecho antes comprobado de un mayor volumen de empleados autonómicos en Andalucía (por 1.000 habitantes), superior al de las otras Comunidades de plena autonomía, podría tener algo que ver con esta circunstancia.

\section{CONCLUSIÓN}

Comparando las disparidades económicas regionales de nuestro país, recientemente Martín Rodríguez (1996) ha señalado que, en el período 19601990. Andalucía y Extremadura disminuyeron proporcionalmente en su $\mathrm{PIB} / \mathrm{Km}^{2}$ mientras otras regiones mejoraban de posición (costa este, archipiélagos y Madrid). Esta situación periférica se acentuó en los últimos años con la penetración creciente de productos desde el exterior. Y así, como apunta Delgado Cabeza (1996), ha sucedido con más de la mitad de los productos agroalimentarios, incluidos más del 60 por 100 de los aceites y grasas, y dos tercios de los vinos, paradójicamente. No es, pues, de extrañar la repercusión de esta situación en el empleo: el 90 por 100 de los nuevos contratos suscritos en la región son eventuales. 
Nos encontramos en un momento en que ciertas zonas periféricas pierden importancia, a la vez que el poder tiende a concentrarse en menor espacio. Frente a los potentes ejes Barcelona-Valencia y Barcelona-Madrid, la conexión Madrid-Sevilla es mucho menor, por no hablar de Andalucía en su conjunto. Los flujos, tanto monetarios como de información y políticos, se debilitan a medida que se baja al Sur.

El azar también ha podido influir en nuestra situación. En el momento clave en que el capital internacional se disponía a invertir en Andalucía, una vez consolidada nuestra posición en la CE, la desaparición del sistema soviético en el Este le abrió unas insospechadas posibilidades que absorbieron desde allí lo que se decidió no emplear aquí. Un breve espacio de tiempo fue suficiente para que Andalucía perdiera aquella oportunidad realmente única. Pero no hay que perder la esperanza.

La región está todavía a tiempo de aunar iniciativas oficiales y empresariales y encaminarse hacia un rumbo en que la modernidad, la innovación y el espíritu de iniciativa no sean unos tópicos manidos, sino algo vivo. En esta Europa de la globalización, de las inmensas redes de información y distribución, nos corresponde un papel activo que debemos asumir, y para el que debemos prepararnos. La dirección política de la Comunidad ha de comprenderlo así, ahora que en la UE parecen estar adquiriendo mayor protagonismo las regiones.

En 1997 se dijo públicamente desde círculos oficiales andaluces que el papel político que correspondía a esta región era ser la verdadera presencia de oposición frente al Gobierno central. En nuestra opinión, al Gobierno andaluz no le corresponde dicho papel, sino el de demostrar que puede ser capaz de gobernar mejor que el central. El buen gobierno se manifiesta mucho más en la eficacia probada que en la crítica indiscriminada.

\section{BIBLIOGRAFÍA}

BANCO DE ESPAÑA (1994): Boletín Estadistico, Madrid.

Barke, M., y Newton, M. (1995): «La iniciativa comunitaria Leader y el desarrollo rural en España: estudio comparativo de la Alpujarra (Granada) y la Loma (Jaén)», en RER, núm. 41.

Caja de Ahorros y Pensiones (1997): Anuario Comercial de España, Univ. Autónoma de Madrid y La Caixa, Barcelona, pp. 175-199.

CAzorla Pérez, J. (1969): «Las subculturas rural y urbana», en el vol. colectivo La concentración urbana en España, CESVC, Madrid.

- (1991): La dinámica cultural en la sociedad andaluza, Consejería de Cultura, Junta de Andalucía, 2 vols. (en colaboración con J. Iglesias de Ussel, R. LÓPEZ PinTor y J. J. Ruiz RICO).

- (1995a): «La inmigración marroquí en España: Datos, opiniones y previsiones», en Rev. Int. de Sociología, 3. a Época, núm. 12, septiembre-diciembre, pp. 117-144.

- (1995b): «El marco económico y la política social en Andalucía, 1995», en Rev. de Estudios Regionales, núm. 42, mayo-agosto, pp. 213-230. 
Cazorla Pérez, J. (1996a): «Indicadores y realidad sociopolítica de las autonomías», en RER, núm. 44 (monográfico sobre las Autonomías en el Estado español), enero-abril, pp. 69-86.

- (1996b): «Estructuras y relaciones de poder en el medio rural español», en Working Papers, núm. 1, Fac. de CC. Políticas y Sociología, Universidad de Granada.

Trabajos publicados por J. CAZORLA concernientes al clientelismo:

- (1989): «Le clientelisme de parti en Espagne», CEMOTI, Fundation Nationale des Sciences Politiques, núm. 7, París.

- (1992): «Del clientelismo tradicional al clientelismo de partido: evolución y características», en Working Papers, núm. 55, ICPS, Barcelona.

- (1994): «El clientelismo de partido en España. El medio rural, la Administración y las empresas», en Working Papers, núm. 86, ICPS, Barcelona.

- (1995): «El clientelismo de partido en la España de hoy: una disfunción de la democracia», en Rev. de E. Políticos, núm. 87, enero-marzo.

Delgado, M., y Román, C. (comps.) (1995): Ocho análisis de la Economía Andaluza, IDR, Sevilla.

Delgado, M. (1996): «Integración y reestructuración de la periferia europea», en $R E R$, núm. 44.

ESECA y UNICAJA (1992): Atlas Económico de Andalucía, Málaga.

ESECA (1996): Informe Económico-Financiero de Andalucía 1996, Caja General, Granada, septiembre. Id. id. 1997.

Maestre Alfonso, J., y otros (sin fecha): Andalucía 2020, Documento de Trabajo, IDR, Sevilla.

Martín RodrígueZ, M. (1996): «Disparidades regionales en España», en RER, núm. 44.

Ministerio de Trabajo y Asuntos Sociales (1996): Estadistica de permisos de trabajo a extranjeros, 1994, Madrid.

Montabes, J. (1996): «La concurrencia electoral en Andalucía», en RER, núm. 44.

Ruiz Avilés, P., y Ulecia GarCía, M. (1995): «La estrategia de desarrollo rural y la iniciativa Leader I», en RER, núm. 41.

SETIÉN, L. (1993): Indicadores sociales de calidad de vida, CIS, Madrid

TORReS LÓPEZ, J. (1996): "Andalucía 1975-95: una larga onda de depresión económica», en $R E R$, núm. 44.

\section{ABSTRACT}

This paper summarises the comparative situation of Andalusia in the global context of Spain's Autonomous Communities and pinpoints various recent and significant indicators of prevailing inequalities (interior and ad extra), which should not necessarily be assimilated with prevailing differences. For the most part, these inequalities have existed for over four decades and they have served to keep Spain's most populated region in a situation of marked economic inferiority for which there is no justification, barring factors such as the shortage of entrepreneurial initiative or the adoption of decisions by those in power, which only recently placed more importance on appearances than on getting to the root of the unemployment, infrastructure and production problems besetting the region. Problems which, for the last century, have kept Andalusia in a position which cannot be explained in terms which ignore its profound, complex and unequal social reality. 